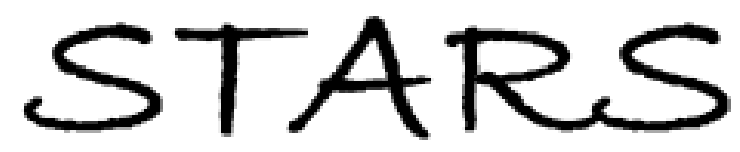

University of Central Florida

STARS

$1-1-2005$

\title{
Comparison of the agglomeration behavior of thin metallic films on $\mathrm{SiO} 2$
}

\author{
P. R. Gadkari \\ University of Central Florida
}

A. P. Warren

University of Central Florida

R. M. Todi

University of Central Florida

R. V. Petrova

University of Central Florida

K. R. Coffey

University of Central Florida

Find similar works at: https://stars.library.ucf.edu/facultybib2000

University of Central Florida Libraries http://library.ucf.edu

This Article; Proceedings Paper is brought to you for free and open access by the Faculty Bibliography at STARS. It has been accepted for inclusion in Faculty Bibliography 2000s by an authorized administrator of STARS. For more information, please contact STARS@ucf.edu.

\section{Recommended Citation}

Gadkari, P. R.; Warren, A. P.; Todi, R. M.; Petrova, R. V.; and Coffey, K. R., "Comparison of the agglomeration behavior of thin metallic films on SiO2" (2005). Faculty Bibliography 2000s. 5198.

https://stars.library.ucf.edu/facultybib2000/5198

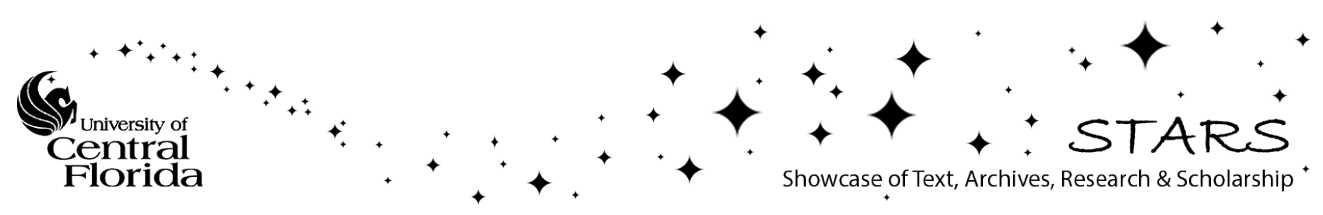




\section{Comparison of the agglomeration behavior of thin metallic films on $\mathrm{SiO}_{2}$}

P. R. Gadkari, A. P. Warren, R. M. Todi, R. V. Petrova, and K. R. Coffey

Citation: Journal of Vacuum Science \& Technology A 23, 1152 (2005); doi: 10.1116/1.1861943

View online: https://doi.org/10.1116/1.1861943

View Table of Contents: https://avs.scitation.org/toc/jva/23/4

Published by the American Vacuum Society

\section{ARTICLES YOU MAY BE INTERESTED IN}

Comparison of the agglomeration behavior of $\mathrm{Au}$ and $\mathrm{Cu}$ films sputter deposited on silicon dioxide Journal of Applied Physics 93, 3270 (2003); https://doi.org/10.1063/1.1556178

Solid-state dewetting of patterned thin films

Applied Physics Letters 95, 251903 (2009); https://doi.org/10.1063/1.3268477

Solid-state dewetting for ordered arrays of crystallographically oriented metal particles Applied Physics Letters 86, 121903 (2005); https://doi.org/10.1063/1.1885180

Dewetting of $\mathrm{Ni}$ and $\mathrm{NiAg}$ solid thin films and formation of nanowires on ripple patterned substrates Journal of Applied Physics 103, 023520 (2008); https://doi.org/10.1063/1.2832758

Capillary instabilities in thin films. I. Energetics Journal of Applied Physics 60, 247 (1986); https://doi.org/10.1063/1.337689

Solid-state dewetting of single- and bilayer Au-W thin films: Unraveling the role of individual layer thickness, stacking sequence and oxidation on morphology evolution

AIP Advances 6, 035109 (2016); https://doi.org/10.1063/1.4944348

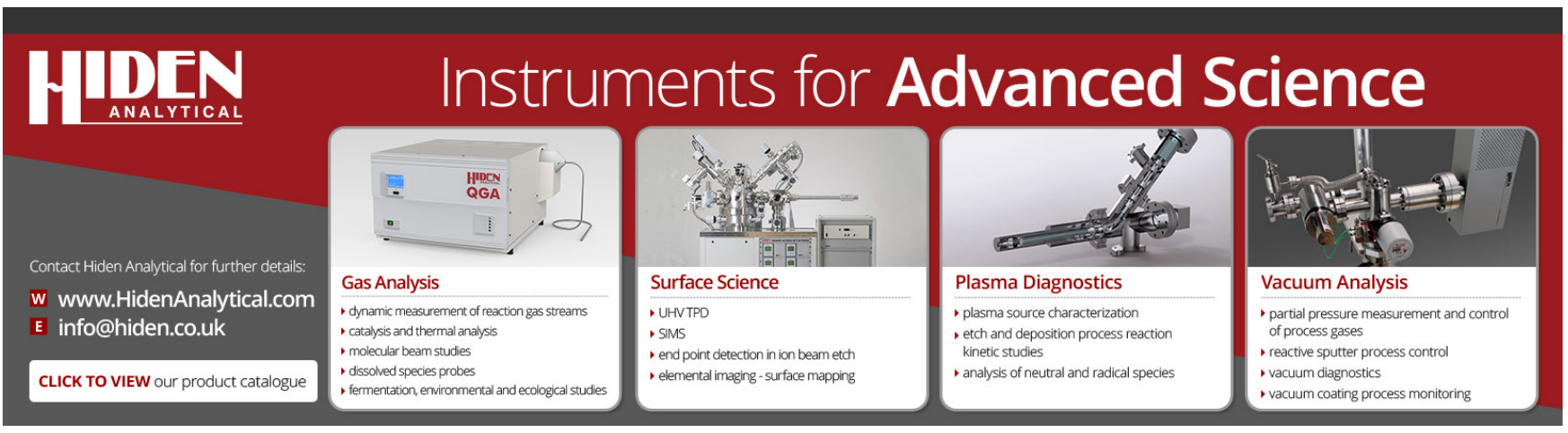




\title{
Comparison of the agglomeration behavior of thin metallic films on $\mathrm{SiO}_{2}$
}

\author{
P. R. Gadkari, A. P. Warren, R. M. Todi, R. V. Petrova, and K. R. Coffey ${ }^{\text {a) }}$ \\ Advanced Materials Processing and Analysis Center, University of Central Florida, Orlando, \\ Florida 32816
}

(Received 1 October 2004; accepted 20 December 2004; published 28 June 2005)

\begin{abstract}
The stability of continuous metallic thin films on insulating oxide surfaces is of interest to applications such as semiconductor interconnections and gate engineering. In this work, we report the study of the formation of voids and agglomeration of initially continuous $\mathrm{Cu}, \mathrm{Au}, \mathrm{Ru}$ and $\mathrm{Pt}$ thin films deposited on amorphous thermally grown $\mathrm{SiO}_{2}$ surfaces. Polycrystalline thin films having thicknesses in the range of 10-100 $\mathrm{nm}$ were ultrahigh vacuum sputter deposited on thermally grown $\mathrm{SiO}_{2}$ surfaces. The films were annealed at temperatures in the range of $150-800{ }^{\circ} \mathrm{C}$ in argon and argon $+3 \%$ hydrogen gases. Scanning electron microscopy was used to investigate the agglomeration behavior, and transmission electron microscopy was used to characterize the microstructure of the as-deposited and annealed films. The agglomeration sequence in all of the films is found to follow a two step process of void nucleation and void growth. However, void growth in $\mathrm{Au}$ and $\mathrm{Pt}$ thin films is different from $\mathrm{Cu}$ and $\mathrm{Ru}$ thin films. Residual stress and adhesion were observed to play an important part in deciding the mode of void growth in Au and Pt thin films. Last, it is also observed that the tendency for agglomeration can be reduced by encapsulating the metal film with an oxide overlayer. () 2005 American Vacuum Society. [DOI: 10.1116/1.1861943]
\end{abstract}

\section{INTRODUCTION}

Thin metallic films are basic components of most semiconductor and magnetic devices. Such films are often deposited at low temperature with microstructures far from equilibrium. The initial film structure can change upon subsequent heating of the film, in use or as part of the device fabrication process. These changes include grain growth and morphological instabilities such as void or "pinhole" formation and the breakup of the film into isolated islands on the substrate surface. The morphological instabilities can result in device failure and are the subject of this work. These instabilities have long been studied ${ }^{1}$ and are still of practical and scientific interest. Films that have a high surface-tovolume ratio and a weak chemical interaction with their substrate are most susceptible to morphological change. The process of the uncovering of the substrate or dewetting of an initially continuous film is known as agglomeration.

Agglomeration is a thermally activated process resulting in a reduction of the free energy of the film-substrate system and can occur well below the melting point of the material by surface and interfacial diffusion. The reduction of filmsubstrate interfacial energy, film-surface interfacial energy and stresses within the film are possible driving forces for agglomeration.

Agglomeration can be considered a two step process; void nucleation and subsequent void growth. The nucleation of voids can be homogeneous or heterogeneous in nature. While the possibility of homogeneous nucleation of void has been considered, ${ }^{2,3}$ heterogeneous nucleation of voids at defects is an accepted means of void formation. Mullins ${ }^{1}$ has demonstrated, via linear stability analysis, that an initially

a) Author to whom correspondence should be addressed; electronic mail: krcoffey@mail.ucf.edu flat surface is stable against small amplitude perturbations and therefore would not form holes spontaneously. Film defects, such as grain boundary triple points, ${ }^{1,2}$ pinholes ${ }^{4}$ and gas bubbles, ${ }^{5}$ can act as sources for heterogeneous nucleation of voids.

Grain boundary grooving describes the tendency of the free surface of a film to form a depression along the intersection of the free surface with a boundary between two adjacent grains. This tendency is typically justified as satisfying a force balance among the two surface/grain and the grain/grain interfacial tensions. ${ }^{1}$ A triple point, where three grains meet, represents a preferred site along the grooved grain boundary for heterogeneous nucleation of voids. Upon annealing, voids are formed in the thin film that exposes part of the substrate surface. With further annealing these voids grow and impinge upon each other resulting in a porous yet partially continuous film. Further annealing eventually forms isolated islands of the film material. This common process based on capillarity ${ }^{6,7}$ has been reported for $\mathrm{Cu},{ }^{5} \mathrm{Pd},{ }^{8} \mathrm{Au},{ }^{6,7,9}$ $\mathrm{Pt}^{10}{ }^{10}$ and Ag. ${ }^{4}$

Recently, Kwon et al. ${ }^{5}$ observed a somewhat different agglomeration process in Au thin films and proposed a different mechanism of "fractal growth." They reported that Au thin films agglomerate through void nucleation and a subsequent fractal growth of the void. According to the fractal growth mechanism, the void nucleates at areas with high stress, not necessarily at grain boundaries, and then voids in the film grow laterally through surface diffusion and undergo perturbations creating void branches. Such branch groups eventually impinge upon each other resulting in the formation of isolated islands similar to those formed in the capillary process. However, no detailed explanation of why the normal capillary process was not observed for their Au thin films was given. 

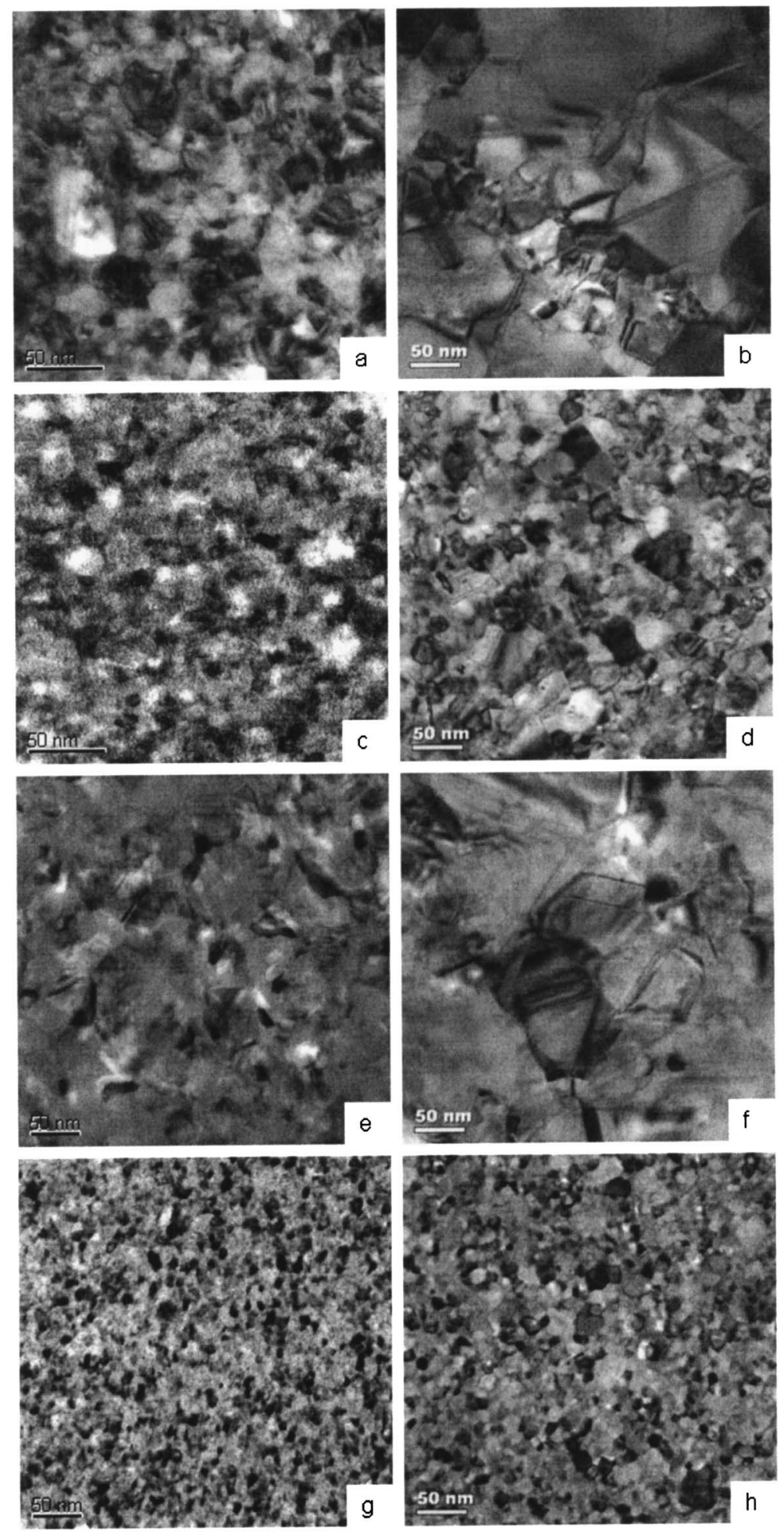

FIG. 1. TEM bright field images of 50-nm-thick Au, Pt, $\mathrm{Cu}$ and $\mathrm{Ru}$ films deposited at 4 mTorr: as-deposited films, before annealing (a) $\mathrm{Au}$, (c) $\mathrm{Pt}$, (e) $\mathrm{Cu}$ and (g) $\mathrm{Ru}$; and after annealing for $30 \mathrm{~min}$ at $300{ }^{\circ} \mathrm{C}$ (b) Au, (d) Pt, (f) $\mathrm{Cu}$ and (h) $\mathrm{Ru}$.
Stresses within the film are also expected to play an important role in kinetics of agglomeration. Srolovitz and Goldiner $^{2}$ reviewed that a film in tensile stress favors agglomeration, whereas a film in compressive stress would lead to formation of holes or hillocks on the surface of the film. However, a film in compressive stress could still agglomerate as a result of film thinning or exposing part of substrate due to formation of holes or hillocks. Moreover, a compressive stress can also lead to transverse buckling, creating blisters on the surface of thin film. ${ }^{11}$

In this work, we studied the morphological thermal stability and agglomeration behavior of $\mathrm{Cu}, \mathrm{Ru}, \mathrm{Au}$ and $\mathrm{Pt}$ thin films. Both the normal "capillary" agglomeration process and a fractal agglomeration process were observed for our 

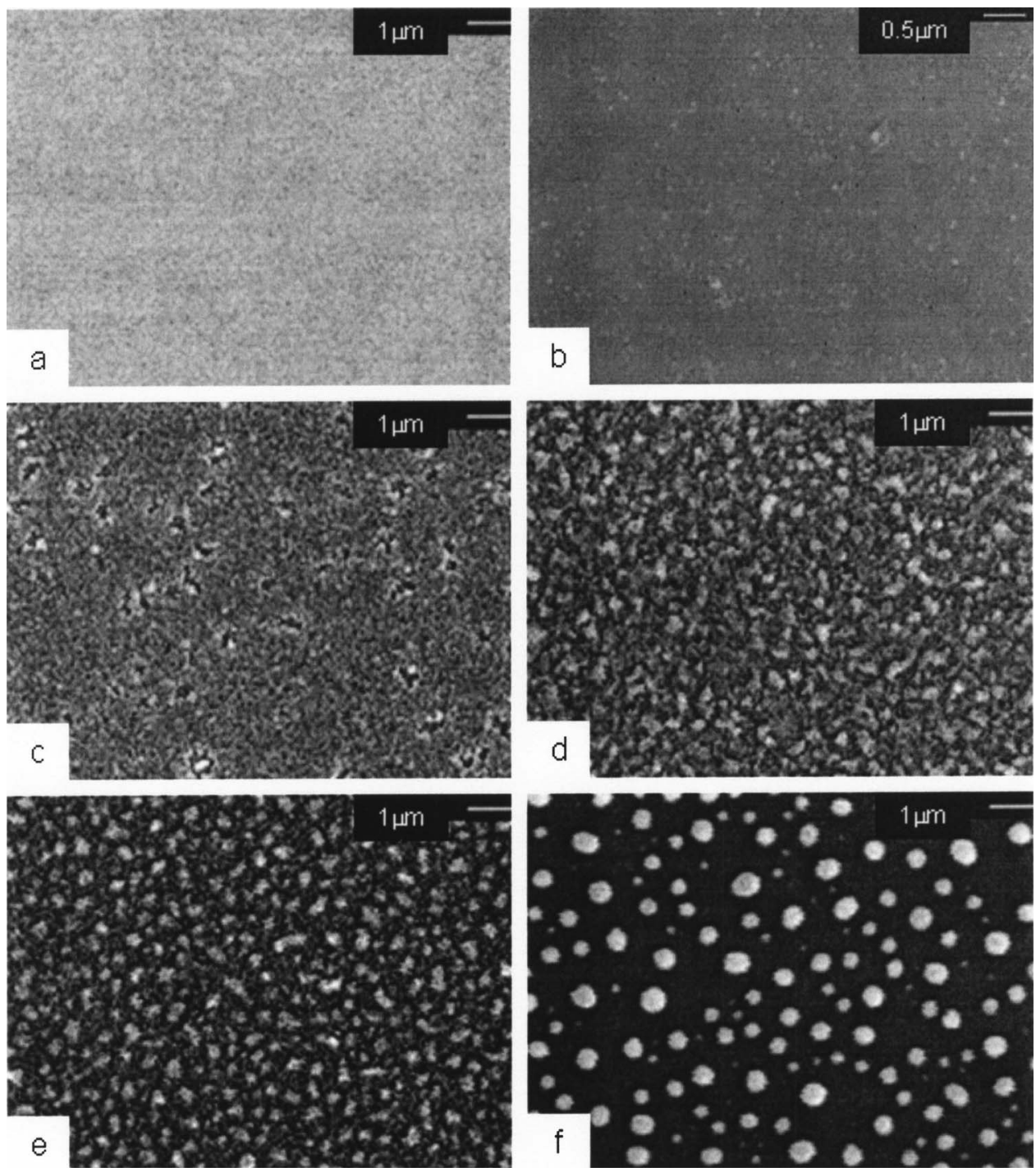

FIG. 2. Capillary growth mode: SEM images of a 20 -nm-thick $\mathrm{Cu}$ film deposited at 4 mTorr: (a) as-deposited, before annealing; and annealed at (b) $250{ }^{\circ} \mathrm{C}$, (c) $350{ }^{\circ} \mathrm{C}$, (d) $450{ }^{\circ} \mathrm{C}$, (e) $550{ }^{\circ} \mathrm{C}$, (f) $700{ }^{\circ} \mathrm{C}$. films. The effect of film thickness, the elimination of the free surface by an encapsulation layer, and high pressure sputter deposition of the films (to reduce film compressive stress) were studied.

\section{EXPERIMENT}

$\mathrm{Cu}, \mathrm{Ru}, \mathrm{Au}$ and $\mathrm{Pt}$ films, with thicknesses in the range of $10-100 \mathrm{~nm}$, were deposited on a thermally grown 100-nm-thick $\mathrm{SiO}_{2}$ layer on a $\mathrm{Si}$ substrate using ultrahigh vacuum dc magnetron sputtering. The system base pressure was approximately $1 \times 10^{-8}$ Torr and the purity of the Ar process gas was maintained by a hot reactive metal getter. Process gas contamination in the deposition chamber at the typical deposition pressure of 4 mTorr was confirmed to be less than $10 \mathrm{ppm}$ (the instrumental sensitivity limit) by closed ion source quadrapole mass spectrometry. Deposition rates were in the range of $6-2 \AA / s$ at $200 \mathrm{~W}$. It was found that an in situ pre-deposition rf cleaning of the substrate prevented the occurrences of pinholes in the as-deposited films and this procedure was adopted for all samples reported here.
To study the effect of an encapsulation layer on agglomeration, additional film samples were prepared with 3- and 10-nm-thick $\mathrm{SiO}_{2}$ films sputter deposited on top of the 50-nm-thick samples of the abovementioned metals. Further, to study the effect of the initial film stress state on the agglomeration behavior of $\mathrm{Au}$ and $\mathrm{Pt}$ films, additional samples were deposited at $20 \mathrm{mTorr}$ of Ar process gas.

The thermal stability of the films was studied by heating the films and characterizing the resultant film microstructure by scanning and transmission electron microscopies (SEM and TEM). The annealing was performed in an ambient of 1 atm of an $\mathrm{Ar}+3 \% \mathrm{H}_{2}$ reducing gas mixture in a quartz tube furnace. Temperatures in the range of $100-1000{ }^{\circ} \mathrm{C}$ were explored and a common annealing time of $30 \mathrm{~min}$ was used. The basic film morphology of the annealed and as-deposited samples was examined in a JOEL $6400 \mathrm{~F}$ scanning electron microscope (SEM). The interpretation of the SEM image contrast as voids and film was confirmed by energy dispersive $\mathrm{X}$-ray analysis. Additionally, samples of the as-deposited and $300{ }^{\circ} \mathrm{C}$ annealed films with a thickness of $50 \mathrm{~nm}$ were 

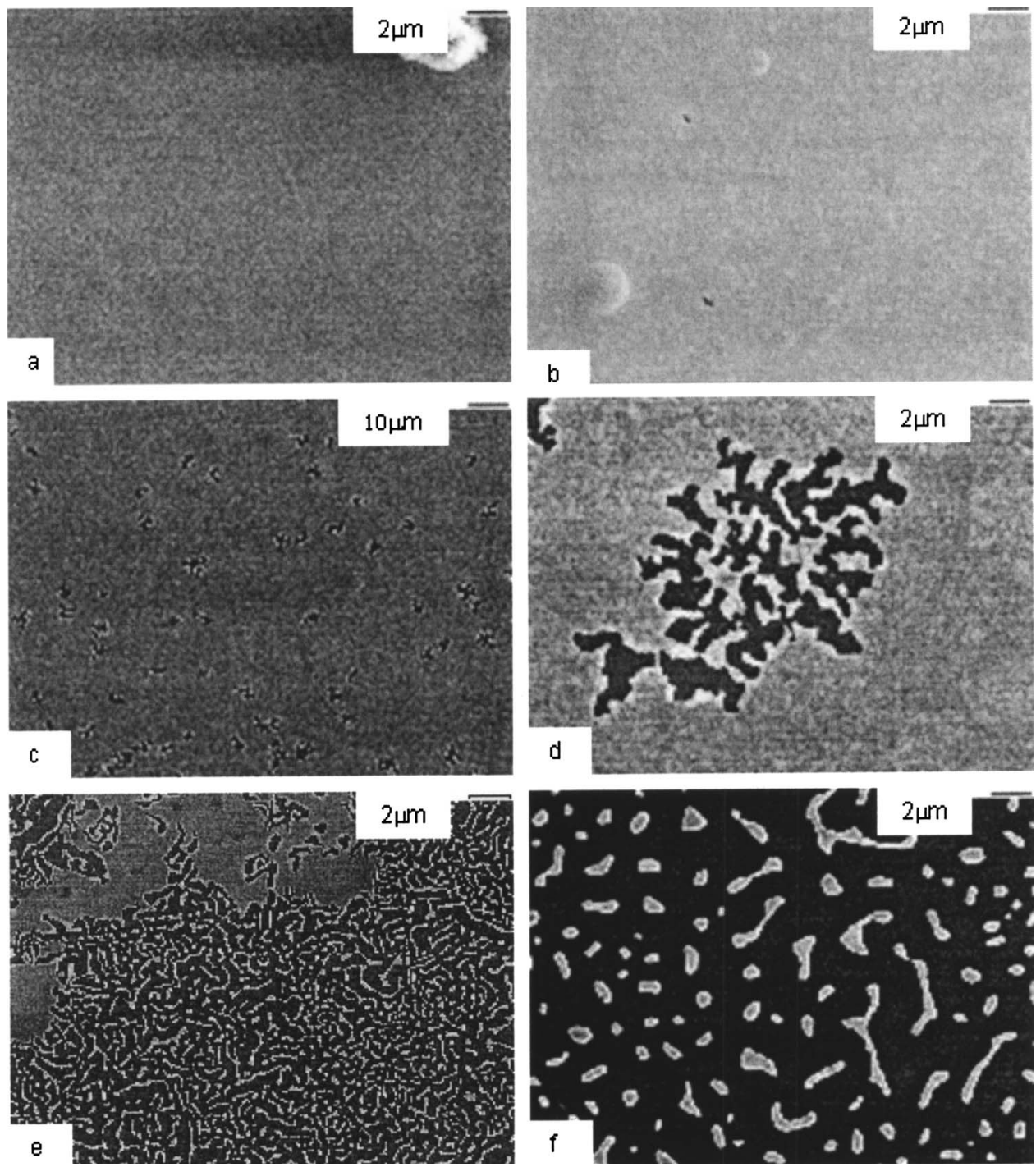

FIG. 3. Fractal growth mode: SEM images of a 20-nm-thick annealed $\mathrm{Au}$ thin film deposited at 4 mTorr: (a) asdeposited, before annealing; annealed at (b) $300{ }^{\circ} \mathrm{C}$, (c) $400{ }^{\circ} \mathrm{C}$, (d) $450{ }^{\circ} \mathrm{C}$ (e) $550{ }^{\circ} \mathrm{C}$, (f) $750{ }^{\circ} \mathrm{C}$. examined by transmission electron microscopy (TEM). One of two techniques was used to prepare plan view TEM specimens: focused ion beam in situ lift out and chemical etching. For the chemical etching, hydrofluoric acid was used to remove the $\mathrm{SiO}_{2}$ under layer and float off the metal film onto a TEM grid. Analysis was carried out in an FEI Tecnai F30 TEM operating at $300 \mathrm{KeV}$, and the images were recorded on a change coupled device (CCD) camera.

\section{RESULTS AND DISCUSSION}

\section{A. Microstructure and grain growth}

Figure 1 shows bright field TEM images of the 50-nm-thick $\mathrm{Au}, \mathrm{Pt}, \mathrm{Cu}$ and $\mathrm{Ru}$ film samples before and after annealing at $300{ }^{\circ} \mathrm{C}$. Only modest grain growth was observed for the $\mathrm{Ru}$ film, whereas a more extensive grain growth was observed for the other metals. The largest increase in grain size, by a factor of 3 , was observed for the $\mathrm{Au}$ thin films, from a $22 \mathrm{~nm}$ average grain size in the asdeposited film to a $69 \mathrm{~nm}$ grain size in the annealed film. Grains in Pt films were observed to double in size, from a
$17 \mathrm{~nm}$ average grain size in the as-deposited film to a $34 \mathrm{~nm}$ average in the annealed film. Grain size in the $\mathrm{Cu}$ films increased by almost a factor of 3 after annealing, from an average grain size of $35 \mathrm{~nm}$ in the as-deposited films to $98 \mathrm{~nm}$ in the annealed film. In the $\mathrm{Ru}$ thin film, the grain growth provided only a modest $20 \%$ increase in grain size, from 12.1 to $14.6 \mathrm{~nm}$. This reduced extent of grain growth in $\mathrm{Ru}$ is consistent with $\mathrm{Ru}$ having the highest melting temperature of the four metals.

The electron diffraction patterns (not shown) from all metals were examined in order to qualitatively assess the crystallographic fiber texture present in these polycrystalline specimens, i.e., if there was a preferred crystallographic axis oriented perpendicular to the film surface. The samples were $\alpha$ tilted from -45 to $45^{\circ}$ and diffraction patterns recorded on the CCD camera. It was found that $\mathrm{Au}$ and Pt films showed a $\langle 111$ ) fiber texture, whereas $\mathrm{Cu}$ and $\mathrm{Ru}$ did not.

From this study, we concluded that, upon annealing, our films undergo grain growth and form a typical metallic thin film microstructure consisting of a single layer of equiaxed grains in the plane of the film. 


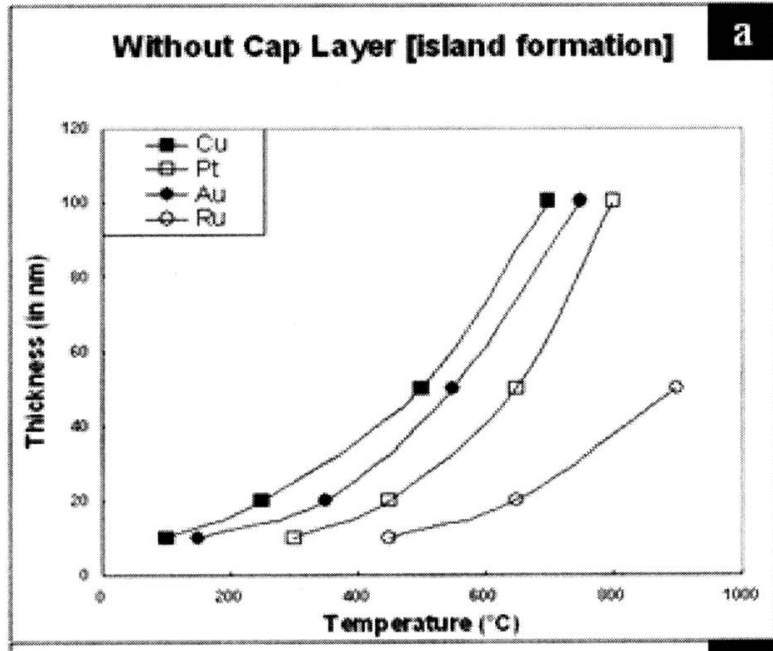

Without Cap Layer [void formation]

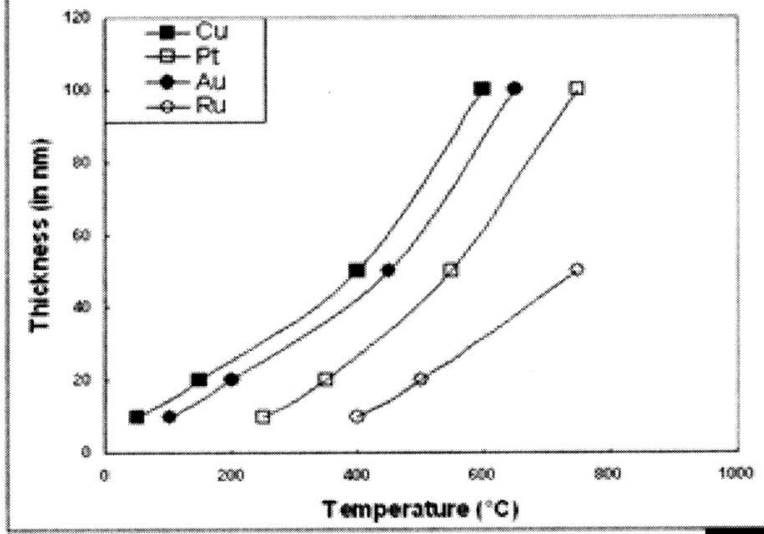

Without Cap Layer [void growth]

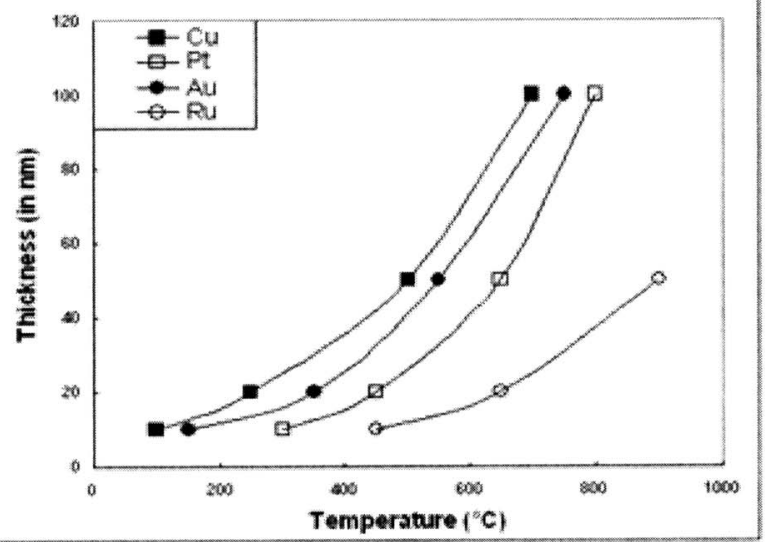

Fig. 4. Effect of thickness on agglomeration behavior. Graph showing thickness vs temperature of films deposited at 4 mTorr: (a) when the film is no longer continuous; (b) when $5 \%$ of the surface is uncovered per $\mu \mathrm{m}^{2}$; (c) when $40 \%$ of the surface is uncovered per $\mu \mathrm{m}^{2}$.

\section{B. Capillary agglomeration process}

The normal, capillary agglomeration process was observed for all of our $\mathrm{Ru}$ and $\mathrm{Cu}$ thin film samples, and an example of this is illustrated by the SEM images of Fig. 2 for

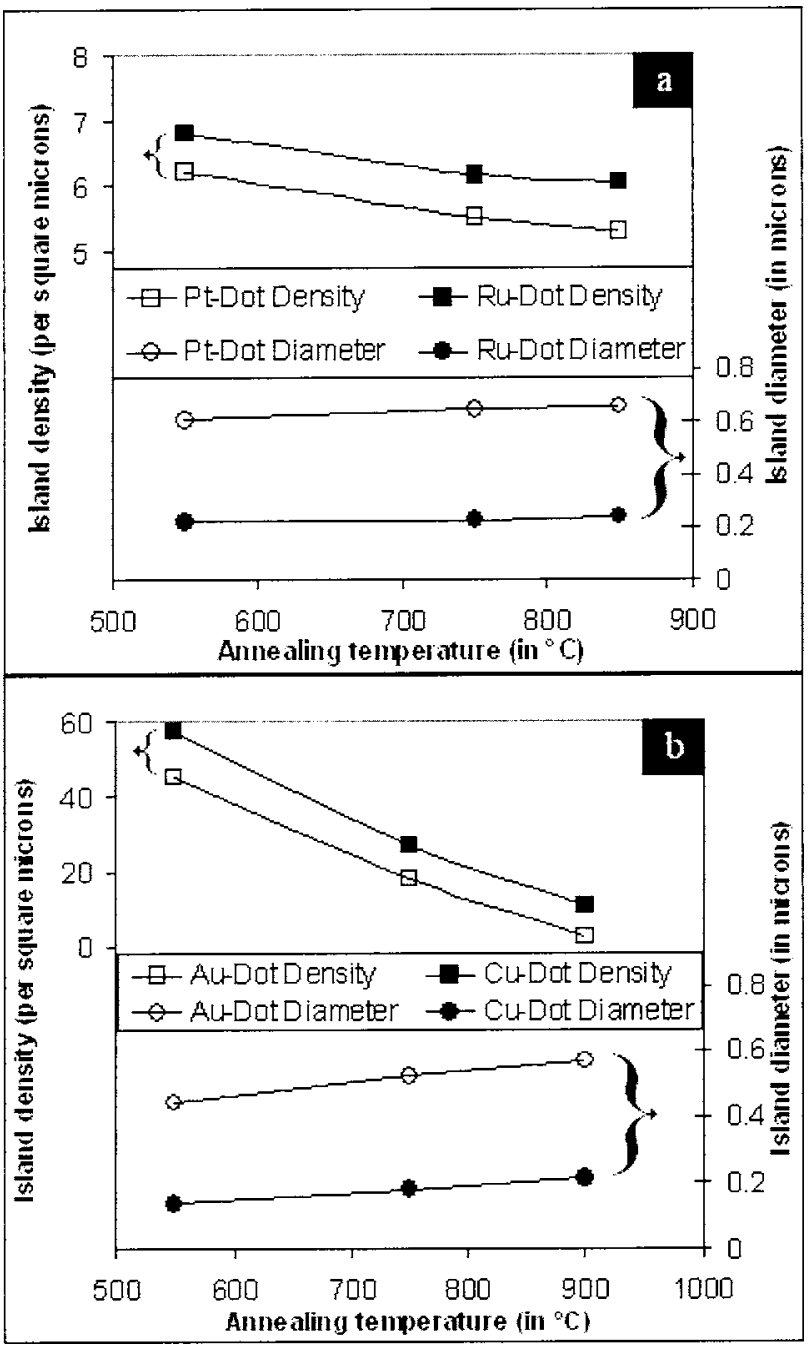

FIG. 5. Island density and island diameter as a function of anneal temperature of films deposited at 4 mTorr.

the case of a $20 \mathrm{~nm} \mathrm{Cu}$ thin film. Figure 2(a) shows the featureless as-deposited thin film. Figure 2(b) shows the image of a film annealed at $250{ }^{\circ} \mathrm{C}$, where some roughening of the film surface can be observed along with initial voids, the latter presumably nucleated at grain boundaries. Further annealing to $350{ }^{\circ} \mathrm{C}$ results in initial voids growing to form obvious holes in the film that expose parts of the substrate, as shown in Fig. 2(c). At $450{ }^{\circ} \mathrm{C}$ this process is further developed, and these holes have grown to impinge upon each other, as shown in Fig. 2(d). The film finally breaks up at $550{ }^{\circ} \mathrm{C}$, and forms small islands on the substrate surface, as shown in Fig. 2(e). At this point film is no longer continuous. Annealing at a yet higher temperature, $700{ }^{\circ} \mathrm{C}$, leads to a reduction of island density and an increase in island size, as shown in Fig. 2(f).

The above process was common to all of the $\mathrm{Cu}$ and $\mathrm{Ru}$ samples studied; however, the annealing temperature needed to generate a given extent of film agglomeration was found to vary systematically with film thickness and encapsulation, and to be different for the two metals, as described below. 

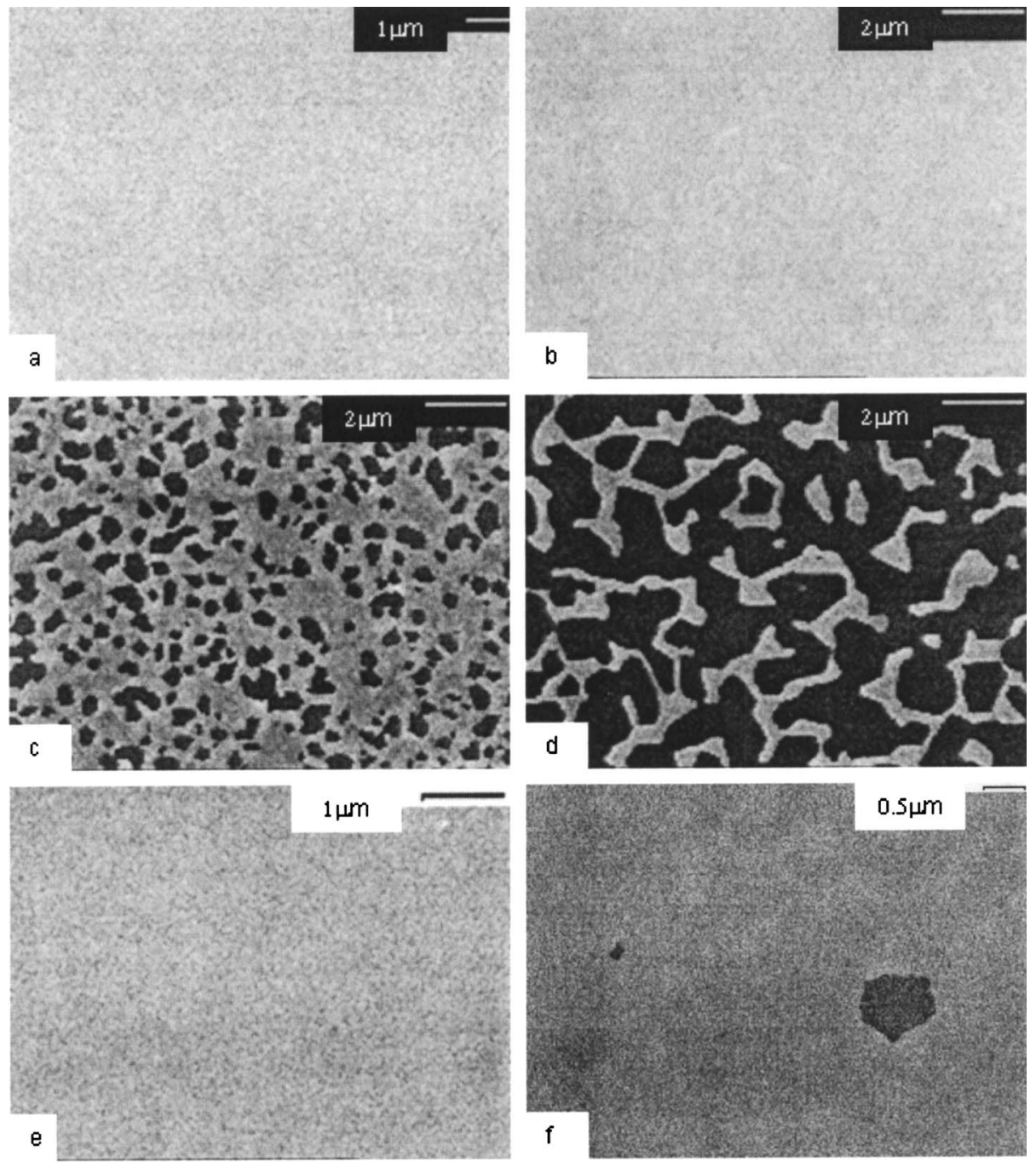

6. Surface morphologies of 50-nm-thick annealed $\mathrm{Au}$ and Pt films deposited at 20 mTorr: $50 \mathrm{~nm} \mathrm{Au}$ films (a) as-deposited, before annealing; annealed at (b) $300{ }^{\circ} \mathrm{C}$, (c) $450{ }^{\circ} \mathrm{C}$, (d) $600{ }^{\circ} \mathrm{C}$. $50 \mathrm{~nm}$ Pt films (e) as-deposited, before annealing; annealed at (f) $600{ }^{\circ} \mathrm{C} ;(\mathrm{g}) 750{ }^{\circ} \mathrm{C}$; (h) $900{ }^{\circ} \mathrm{C}$.
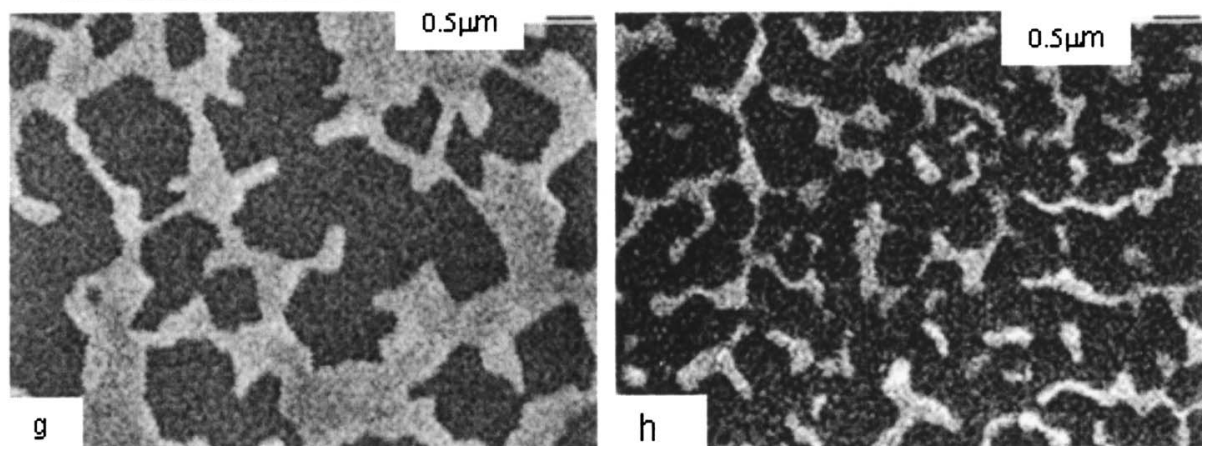

\section{Fractal agglomeration process}

Voids in the Au and Pt thin films were typically observed to grow in a branched manner, described as fractals. The main feature of the fractal agglomeration process is that the voided regions appear to be initially elongated, linear structures and not the regions of minimum perimeter associated with capillary forces. An illustrative example is shown in Fig. 3, which consists of SEM images of a 20-nm-thick Au film. The as-deposited Au film is shown in Fig. 3(a). After annealing at $300{ }^{\circ} \mathrm{C}$, as shown in Fig. 3(b), voids were found to nucleate in $\mathrm{Au}$ thin films creating a hole in the film and exposing the substrate. Figure 3(b) also shows large circular blisters in the Au film that will be described in further detail below. Figures 3(c)-3(e), corresponding to anneal temperatures of 400,450 , and $500{ }^{\circ} \mathrm{C}$, respectively, show the distinctive fractal appearance of the voids as they grow larger in size. Eventually, island morphology similar to that of the capillary agglomeration process results, as shown in Fig. 3(f), for a sample annealed to $700{ }^{\circ} \mathrm{C}$. This fractal agglomeration process was observed for all the Au and Pt thin films we studied except the thinnest, $10 \mathrm{~nm}$ thick, Au films and the $\mathrm{Au}$ and $\mathrm{Pt}$ films deposited at higher Ar pressure. 

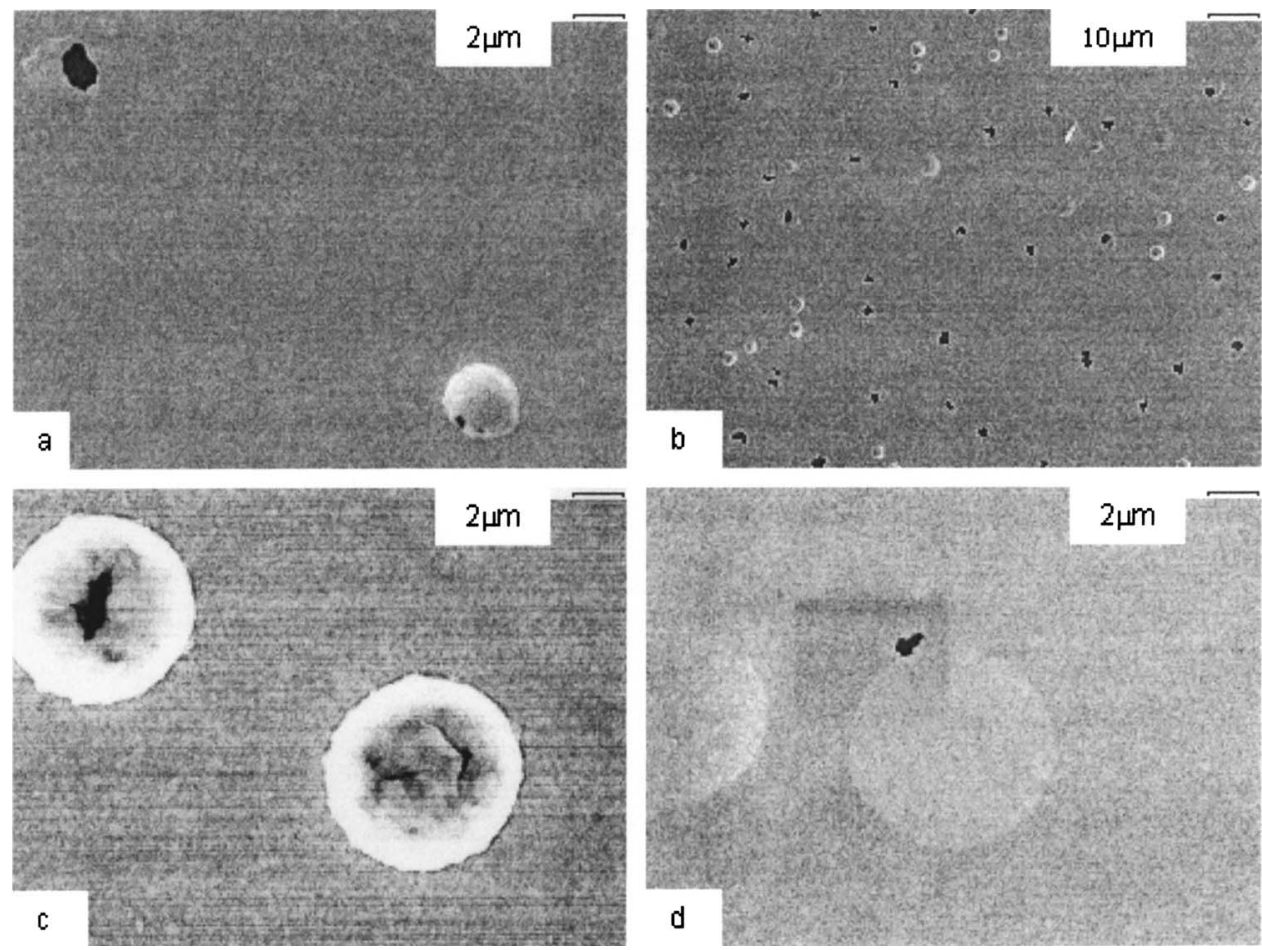

FIG. 7. Void nucleation at blisters observed in $\mathrm{Au}$ and $\mathrm{Pt}$ films deposited at 4 mTorr: (a) 20-nm-thick Pt film annealed at $300{ }^{\circ} \mathrm{C}$; (b) 20 -nm-thick $\mathrm{Au}$ film annealed at $450{ }^{\circ} \mathrm{C}$; (c) 50-nm-thick $\mathrm{Au}$ film annealed at $600{ }^{\circ} \mathrm{C}$ and (d) $50 \mathrm{~nm} \mathrm{Pt}$ film annealed at $600{ }^{\circ} \mathrm{C}$.

\section{Film thickness and agglomeration}

For each metal, thicker film samples required a higher annealing temperature to be used to achieve the same extent of agglomeration as the thinner films. One criterion for the extent of agglomeration is island formation, i.e., the percolation threshold, the point at which the film becomes discontinuous and is no longer electrically conductive end to end. This criterion is relevant to device applications of metal films and was also used by us to summarize the effect of film thickness and annealing temperature upon agglomeration. This data are shown graphically in Fig. 4, where the thickness at which the percolation limit was exceeded is shown as a function of temperature of anneal for each of the four metals. The monotonic increase in thickness with anneal temperature is expected. Other criteria for studying the agglomeration were based on void formation and void growth. For this work, void formation was defined as the point where 5\% of a $1 \mu \mathrm{m}^{2}$ substrate area was uncovered or exposed, and void growth as the point where an average of $40 \%$ of a $1 \mu \mathrm{m}^{2}$ substrate area was exposed. Figures 4(b) and 4(c) show similar data, but for these two different criteria. We can infer from these graphs that thicker films tend to maintain morphological stability at higher annealing temperatures. The entire agglomeration sequence for 50- and 100-nm-thick $\mathrm{Ru}$ films could not have been studied, as is apparent from the graph, because the range of anneal temperatures explored was not high enough to generate discontinuous Ru films.

\section{E. Coarsening of discontinuous films}

The annealing temperature was varied from 350 to $900{ }^{\circ} \mathrm{C}$ with a fixed annealing time of 30 min to study the effect of temperature on agglomeration. The average island diameter and density as a function of annealing temperature is presented in Fig. 5.

Figure 5(a) presents the surface morphologies of 10-nm-thick $\mathrm{Ru}$ and $\mathrm{Pt}$ films and Fig. 5(b) illustrates 20-nm-thick $\mathrm{Cu}$ and $\mathrm{Au}$ films. From Fig. 5, we learn that with increasing annealing temperature the density of islands decreases and the size of islands increases. This dependence can be credited to the coalescence of islands at high temperatures.

\section{F. Blisters in Au and Pt thin films}

The circular blisters that can be seen in Fig. 3(b) were usually present on the $\mathrm{Au}$ and $\mathrm{Pt}$ films deposited at low pressure (4 mTorr), but were always absent on the $\mathrm{Cu}$ and $\mathrm{Ru}$ films that were similarly deposited. The blisters were present on almost all of the annealed thin films of $\mathrm{Au}$ and $\mathrm{Pt}$ and on the as-deposited films of $\mathrm{Au}$ and $\mathrm{Pt}$, except for the 10-nm-thick as-deposited Au film. They were also observed to grow with time on the as-deposited films. The case of the $10 \mathrm{~nm} \mathrm{Au}$ film is discussed later in the next section. The blisters are believed to be areas of film delamination. Kwon et $a .^{5}$ and Hummel et al. ${ }^{9}$ also observed blisters in their films, and they credited Ar collecting at the film-substrate interface as the cause for this delamination. They assumed the blisters to be Ar bubbles formed from Ar gas atoms incorporated in the film during sputter deposition and further concluded that these blisters had no effect on the agglomeration sequence. ${ }^{5}$ While trace Ar amounts can usually be found in sputtered films, the diffusion of Ar atoms over the micronscale distances required to collect $\mathrm{Ar}$ at a blister location seems unlikely compared to the Ar atoms simply diffusing 

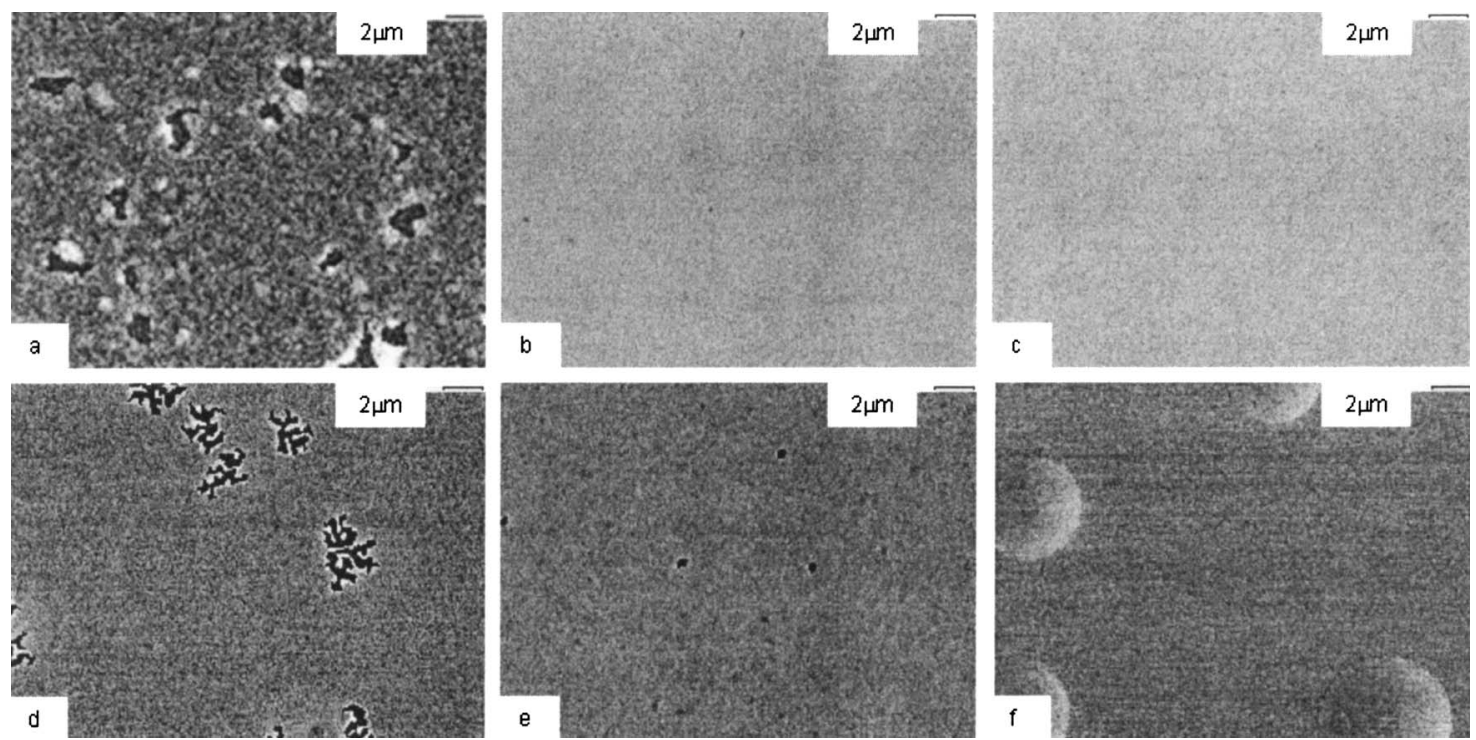

FIG. 8. Effect of encapsulation layer on agglomeration behavior: SEM images of annealed 50-nm-thick $\mathrm{Cu}$ and Pt films deposited at $4 \mathrm{mTorr}$ : Cu films annealed at $500{ }^{\circ} \mathrm{C}$ (a) without cap layer; (b) with $3 \mathrm{~nm}$ cap layer; (c) with $10 \mathrm{~nm}$ cap layer. Pt thin films annealed at $650{ }^{\circ} \mathrm{C}$ (d) without cap layer; (e) with $3 \mathrm{~nm}$ cap layer; (f) with $10 \mathrm{~nm}$ cap layer.

the $10-50 \mathrm{~nm}$ required to escape from the top surface of the film. Instead, we interpret these blisters to be circular regions of film delamination resulting from the combination of residual compressive stress in the film and poor adhesion of $\mathrm{Au}$ and $\mathrm{Pt}$ to the $\mathrm{SiO}_{2}$ substrate. Only the as-deposited thinnest Au film, at $10 \mathrm{~nm}$, failed to develop blisters with time, consistent with this model. Also consistent with this model are the separate observations of film adhesion using a qualitative "scotch tape test," which indicated stronger film-substrate adhesion for $\mathrm{Cu}$ and $\mathrm{Ru}$ films, where blisters were not observed, compared to the $\mathrm{Au}$ and $\mathrm{Pt}$ films.

\section{G. Fractals, blisters and stress}

To test our assumption of blisters resulting from a combination of compressive stress and poor film adhesion to the substrate, we deposited 10- and 50-nm-thick Au and Pt films at a higher sputtering gas pressure of $20 \mathrm{mTorr}$. Since the initial compressive stress in the film is expected to be reduced by a higher Ar pressure during deposition, ${ }^{12}$ we anticipated an elimination or reduction in the blister formation of these films. This did, indeed, occur. No blisters were found on the films deposited at high gas pressure, for both the annealed and the as-deposited samples. These films also had qualitatively better adhesion than the films deposited at 4 mTorr. Unexpectedly, these films all showed a capillary agglomeration process instead of the fractal agglomeration process observed for the Pt and the thicker Au films deposited at lower pressure. Figure 6 shows SEM images of the capillary agglomeration process for the $50 \mathrm{~nm} \mathrm{Au}$ and Pt thin films deposited at high gas pressure. These films were observed to agglomerate following a process similar to that observed in the $\mathrm{Cu}$ and $\mathrm{Ru}$ thin films. The blister-free, 10-nm-thick Au film was also observed to follow a capillary agglomeration process. Significantly, the Au and Pt films that did not have a fractal agglomeration process did not have delamination blisters. In our work, these two observations are correlated. We think this coincidence of delamination blisters and fractal agglomeration is significant, and suggests that the fractal agglomeration may be a morphological instability that occurs simultaneously from both top and bottom surfaces of a free-standing (or nearly free-standing) film, rather than an instability starting from the free surface of an adherent film with subsequent de-wetting of the film from the substrate surface.

This view is supported by the observation that the delamination blisters, when present, were also found to be a more probable region for void nucleation in $\mathrm{Au}$ and $\mathrm{Pt}$ thin films. Figure 7 shows SEM images of four examples of $\mathrm{Au}$ and $\mathrm{Pt}$ films that illustrate this tendency. In all of the images, voids are formed in the blister region. It should be pointed out that the film portion that is free standing in the blister region is susceptible to grain boundary grooving on both top and bottom surfaces. Grain boundary triple points are expected to be coincident on the top and bottom surfaces of these films, due to their columnar grain structure. For such a film microstructure, a void would be expected to nucleate more readily in the free-standing portions of the film than in an adhered region.

A fractal appearance as the film breaks up is also consistent with the "nearly free-standing" view proposed here for the low pressure deposited Au and Pt films. An initial void can propagate more readily as a linear defect in the freestanding film without the mass transport needed to move film atoms away from the voided region in an adhered film.

\section{H. Encapsulation and agglomeration}

The study of a free-standing film, with two free surfaces, is experimentally difficult. However, it is experimentally 


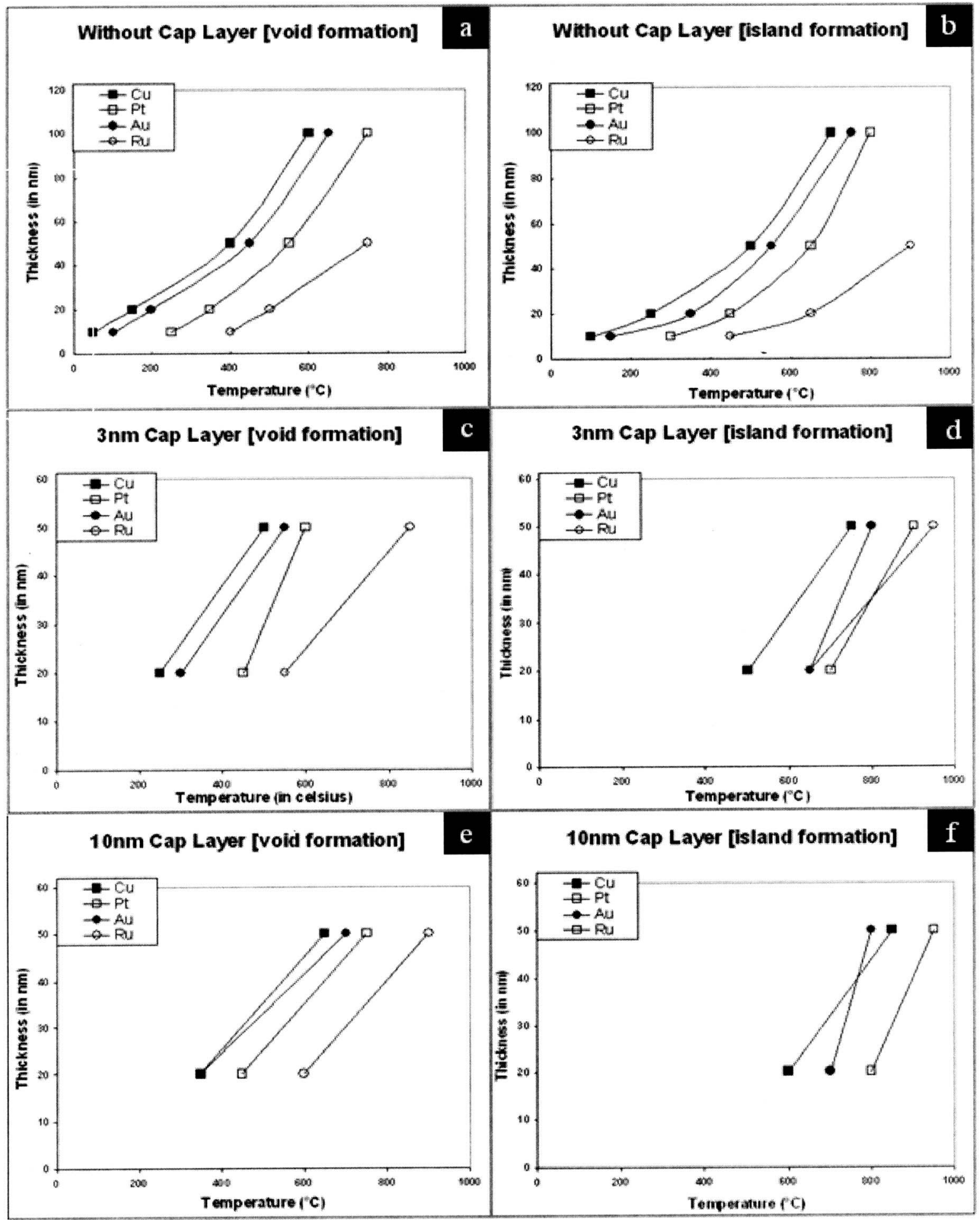

FIG. 9. Effect of encapsulation layer on agglomeration behavior. Graph showing thickness vs temperature, of films deposited at 4 mTorr, at: (a), (c) and (e) void nucleation; (b), (d) and (e) island formation.

convenient to prepare samples with no free surfaces, by the sputter deposition of a $\mathrm{SiO}_{2}$ encapsulation layer on top of the metal films. We prepared samples having 3- and 10-nm-thick encapsulation layers on 20- and 50-nm-thick films of all four metals studied, and annealed these as before to study the agglomeration process. Figure 8 shows SEM images of the
$\mathrm{Cu}$ and $\mathrm{Pt}$ thin films as illustrative examples. For all cases, the presence of an encapsulation layer reduced the tendency of the film to agglomerate, with the thicker encapsulation layer having a stronger effect. These tendencies are summarized in Fig. 9, which shows the thickness at which the initial void formation and percolation threshold is reached for all 
four metals as a function of anneal temperature. The greater effectiveness of the thicker encapsulation layers to prevent film agglomeration is consistent with the encapsulation layers having a primarily mechanical effect to reduce the grain boundary grooving (playing a role in the force balance), rather than a surface chemistry effect that modifies the mass transport on the film top surface. The films used for this series of experiments were all deposited at 4 mTorr, and both fractal agglomeration for Pt and Au and capillary agglomeration for $\mathrm{Cu}$ and $\mathrm{Ru}$ were observed as before, indicating that while the kinetics of the agglomeration process were slowed by the encapsulation layer, the fundamental driving forces for the two agglomeration processes remained similar.

\section{CONCLUSIONS}

We have investigated the agglomeration behavior of $\mathrm{Cu}$, $\mathrm{Ru}, \mathrm{Au}$ and $\mathrm{Pt}$ thin films of thicknesses in the range of $10-100 \mathrm{~nm}$ and reported on the extent of and the qualitative appearance of the film agglomeration as a function of annealing temperature. The films studied were observed to have weak or no fiber texture and a normal extent of grain growth, forming a typical, equiaxed, thin film metallic microstructure. We have found that $\mathrm{Au}$ and $\mathrm{Pt}$ films deposited at 4 mTorr have circular delaminations, relatively poor adhesion, and have a fractal appearance during agglomeration. $\mathrm{Cu}$ and $\mathrm{Ru}$ thin films deposited at the same pressure have better adhesion, do not have delaminations, and agglomerate with the more common appearance of an increasing density and size of voids. Au and Pt films deposited at 20 mTorr have improved adhesion, an absence of delaminations, and an agglomeration appearance similar to that of the $\mathrm{Cu}$ and $\mathrm{Ru}$ thin films. We observed that the delaminated regions, when present, were preferred areas for initial void formation. We postulate that the fractal appearance of the agglomerating films is due to the rapid propagation of linear void defects in free-standing and weakly adhering films.

Samples prepared with a $\mathrm{SiO}_{2}$ encapsulation layer on top of he metal films were observed to follow a similar agglomeration process as the un-encapsulated films of the same metal, but with significantly higher annealing temperatures required to develop the same extent of agglomeration. A 10-nm-thick encapsulation layer was found to have a stronger effect than a $3 \mathrm{~nm}$ layer, and this was postulated to be due to a mechanical hindrance of grain boundary grooving, and hence void initiation, at the film top surface.

Our results suggest that future studies should include a quantitative study of the relationship of film stress to the agglomeration morphology, and a cross-sectional TEM study of the fractal agglomeration samples, to test the hypothesis that grain boundary grooving is occurring on both top and bottom film surfaces.

${ }^{1}$ W. W. Mullins, J. Appl. Phys. 28, 333 (1957).

${ }^{2}$ D. J. Srolovitz and M. G. Goldiner, JOM 31, (1995).

${ }^{3}$ D. J. Srolovitz and S. A. Safran, J. Appl. Phys. 60, 247 (1986).

${ }^{4}$ K. Sieradzki, K. Bailey, and T. L. Alford, Appl. Phys. Lett. 79, 3401 (2001).

${ }^{5}$ J.-Y. Kwon, T.-S. Yoon, K.-B. Kim, and S.-H. Min, J. Appl. Phys. 93, 3270 (2003).

${ }^{6}$ E. Jiran and C. V. Thompson, Thin Solid Films 208, 23 (1992).

${ }^{7}$ E. Jiran and C. V. Thompson, J. Electron. Mater. 19, 1153 (1990).

${ }^{8}$ M. Eriksson, I. Olsson, R. Erlandsson, U. Helmersson, and L.-G. Ekedahl, Thin Solid Films 342, 297 (1999).

${ }^{9}$ R. E. Hummel, R. T. DeHoff, S. Matts Goho, and W. M. Goho, Thin Solid Films 78, 1 (1981).

${ }^{10}$ S. L. Firebaugh, K. F. Jensen, and M. A. Schmidt, J. Microelectromech. Syst. 7, 128 (1998).

${ }^{11}$ L. B. Freund and S. Suresh, Thin Film Materials: Stress, Defect Formation and Surface Evolution (Cambridge University Press, Cambridge, UK, 2004).

${ }^{12}$ D. W. Hoffman and J. A. Thornton, J. Vac. Sci. Technol. 20, 355 (1982). 